\title{
Mimarlık Öğrencilerinin Perspektif Çizme Başarısı ile Öğrenme Stilleri Arasındaki ilişki
}

Yrd. Doç. Dr. Yasemin Erkan Yazıcı

\section{Özet}

Bu araştırmada, İstanbul Kültür Üniversitesi, Mimarlık Bölümü, Mimari Perspektif dersini alan öğrencilerin perspektif çizme başarısı ile öğrenme stilleri arasındaki ilişkinin tespit edilmesi amaçlanmıştır. Bu amaçla, dersi alan 11 öğrenciye Kolb'un Öğrenme Stili Envanteri uygulanmıştır. Elde edilen verilere göre 3 öğrencinin yerleştiren, 3 öğrencinin değiştiren, 2 öğrencinin ayrıştıran ve 3 öğrencinin özümseyen öğrenme stiline sahip olduğu tespit edilmiştir. Daha sonra yapılan atölye çalışması sonucunda elde edilen çizimler analiz edilmiş ve öğrencilerin öğrenme stilleri ile karşılaştııı ımşır. Çalışma sonunda öğrencilerin perspektif çizme başarıı ve öğrenme stilleri arasında anlamlı sonuçlar elde edilmiştir.

\section{THE RELATIONSHIP BETWEEN THE PERSPECTIVE DRAWING PERFORMANCE AND LEARNING STYLES OF ARCHITECTURE STUDENTS}

\footnotetext{
Abstract

This paper investigates the relationship between the learning styles and perspective drawing performance of the students enrolled in the Architectural Perspective course in the Department of Architecture of Istanbul Kultur University. For this purpose, Kolb's Learning Style Inventory was used to identify the learning styles of 11 students taking the course. It was found that 3 of the students were accomodators, 3 of the students were divergers, 2 of the students were convergers and 3 of the students were assimilators. Drawings obtained from a workshop conducted afterwards were analyzed and compared with the perspective drawing performance of students. Results of this study indicate that there is a significant relationship between the perspective drawing performance and learning styles of students.
}

\section{Anahtar} Kelimeler

Perspektif Çizme Başarısı

Öğrenme Stilleri

Kolb Öğrenme Stili Envanteri

\section{Keywords}

Perspective Drawing Performance

Learning Styles

Kolb's Learning Styles Inventory 


\section{Giriş}

Her birey, yaşam boyunca çevresi ile ilişkisinde, algılarken, amaçlarına ulaşırken ve problem çözerken farkı davranış sergiler. Bu süreçte birey; farklı yollarla veri toplar, bu verileri farklı şekillerde sınıflar, bunlardan farklı sonuçlara ulaşır, farklı kararlar verir ve bu kararları farklı biçimde uygular. Böylece her bireyde farklı bilgi işleme biçimleri ve bir iş yapılırken kullanılan farklı yöntemler gelişir (Erkan Yazııı, 2010).

Öğrenme merkezli öğretimin öneminin artmasıly birlikte öğrenenlerin sahip olduğu özellikler de ön plana çıkmış, bu durum öğrenme stilleri ile ilgili araştırmaların da artmasına neden olmuştur (Öztuna, 2013).

$\mathrm{Bu}$ makalede, öğrenme stillerinin perspektif çizme başarısı üzerindeki etkisi araştırılmışır. Uygulama grubu olarak, 2013-2014 güz yarıyılı, İstanbul Kültür Üniversitesi, Mimarlık Bölümünde yer alan Mimari Perspektif dersini alan öğrenciler seçilmiştir.

Üç boyutlu düşünme, algılama ve ifade edebilme becerisinin geliştirilmesinin amaçlandığı Mimari Perspektif dersinde, bu beceriler paralel ve konik perspektiflerin uygulamalarının yapılmasıyla kazandırımaya çalısılmaktadır. Yapılan uygulamalarda algılama, ifade edebilme ve detaylara dikkat etmede öğrenciler arasında farklııklar tespit edilmiştir. Yapılan çalışmalar (Kolb, 1984; Kolb ve Kolb, 2005; Aşkar ve Akkoyunlu, 1993; Demirbaş ve Demirkan, 2003; Hearron, 1991; Ismail, 1982;Cesur, 2008;Öztuna, 2013; Erkan Yazıcl, 2010, Ekici, 2003) bu farkılıkların öğrenme stilleriyle ilişkili olabileceği yönündedir. Saptanan bu farklılıklar bu konuda araştırma yapılmasına neden olmuştur.

Makale, kuramsal ve atölye çalışması olmak üzere iki kısımdan oluşmaktadır. Kuramsal bölümde öğrenme stilleri hakkında genel bilgi verilmiş ve çalışma için seçilen öğrenme stili belirleme yöntemi, bu konuda yapılmış örneklerle açılanmaya çalışılmışıı. Sonraki bölümde, atölye çalışmasında yapılan uygulama açıklanarak, kuramsal bilgiler çerçevesinde analiz edilerek değerlendirilmiştir. 


\section{Öğrenme Stilleri}

Öğrenme süreci her birey için aynı değildir. Öğrenme stili bilgiyi kavrama ve işlemede kişisel olarak tercih edilen yol olarak tanımlanabilir (Kolb ve Kolb, 2005). Öğrenme stili, algılama, bilgiyi zihne yerleştirme, geçmiş yaşantılar, çevre etkisi, kalıtsal özellikler gibi konularla ilgili çok boyutlu bir kavramdır (Cesur, 2008). Öğrenme stilleriyle ilgili olarak farklı sınıflandırmalar, modeller ortaya çıkmış ve öğrenme stillerini belirlemek için farklı ölçekler geliştirilmiştir. Gregorc,Bernice McCarthy 4-MAT, Dunn ve Dunn,Myers-briggs ve Kolb öğrenme stili ölçekleribu ölçeklerden başlıcalarıdır (Ekici, 2003).

Kolb ögrenme stili modelinin temelini Kolb'un Yaşantısal Öğrenme Kuramı oluşturmaktadır. Yaşantısal Öğrenme Kuramına göre bireyler kendi yaşantılarından ve deneyimlerinden öğrenirler. Yaşantısal öğrenmede 4 farklı öğrenme yeteneği vardır. Bunlar; somut yaşantı (hissederek), soyut kavramsallaştırma (düşünerek), aktif yaşantı (yaparak) ve yansıııcı gözlem (izleyerek)dir. Kolb'a göre öğrenme sürecinde algı ve işlem olmak üzere iki boyut bulunmaktadır. Algı boyutu, somut yaşantıdan soyut kavramsallaştırmaya uzanır ve bireyin nasıl algıladığını açıklar; işlem boyutu ise aktif yaşantıdan yansıtıcı gözleme uzanır ve bireyin bilgiyi nasıl işlediğini açıklar (Kolb, 1984).

Kolb öğrenme stili modelinde(1984) bireyin öğrenme stilini, bir öğenin tek başına belirlemediğini, dörtöğenin bileşiminin önemli olduğunu vurgulamıştır. Bu bileşimler doğrultusunda, "değiştiren", "özümseyen", "ayrıştıran" ve "yerleştiren" olmak üzere dört öğrenme stili ortaya çıkmaktadır (Şekil 1).

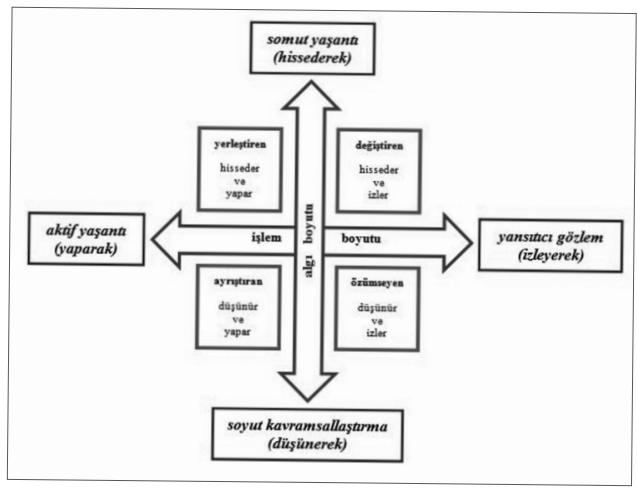

Şekil 1:Kolb'un yaşantısal öğrenme modeli (Kolb, 1984) 
Sezgilere önem verme, planlama yapma, kararları yürütme, yeni deneyimler içinde yer alma, grupla çalışma, deneme yanılma yoluyla problem çözme "yerleştiren" öğrenme stiline sahip bireylerin özellikleri arasında yer almaktadır. Öğrenme sürecinde bu bireyler açık fikirli olmakta ve değişimlere karşı kolaylıkla uyum sağlamaktadırlar.

Yeni düşünceler üretme, farklı açılardan bakma, duyarlı olma, problem çözerken hayal gücünü kullanma, grupla çalısmayı tercih etme, değer ve anlamların farkında olma, kendi duygu ve düşüncelerini önemseme "değiştiren" öğrenme stiline sahip bireylerin belli başlı özellikleridir. Bu bireyler, beyin fırtınasındaolduğu gibi fikirlere odaklanma ve fikirleri ilişkilendirme konusunda yeteneklidirler. Öğrenme sürecinde kendi düşünce ve duyguları öncelikli olarak önemlidir. Değiştiren öğrenme stiline sahip bireyler sabırlı, nesnel, dikkatli yargılarda bulunan fakat bir eylemde bulunmayan tutum sergilemektedirler.

Tek doğru yanıtlı soruları başarıyla çözme, düşünerek ve yaparak öğrenme, problem çözme, teknik konularla ilgilenme, plan yapma, fikirleri mantıksal analiz etme, karar verme, uygulamaya önem verme "ayrıştıran" öğrenme stiline sahip bireylerin özellikleri arasındadır. Bu bireyler öğrenme sürecinde planlı çalışmayı severler, problem çözerken sistemli olarak planlama yaparlar.

Kuram ve ilkeleri önemseme, kavramsal modeller oluşturma, soyut kavramlar ve fikirler üzerinde odaklanma, parçadan bütüne gitme "özümseyen" öğrenme stiline sahip bireylerin belli başlı özellikleridir. Bu öğrenme stilindeki bireylere sunulan bilgi, sıralı, mantıkı ve ayrıntılı olmalıdır. İşitsel ve görsel sunumları içeren ders anlatımlarını tercih ederler. Öğrenme durumunda, soyut kavramlar ve fikirler üzerinde odaklanırlar (Guild \& Garger, 1998).

Bu çalışmada Kolb Öğrenme Stili Envanteri'nin Aşkar ve Akkoyunlu (1993) tarafındanTürkçe'ye uyarlanmış hali kullanıımıştır. Envanterin geçerlik ve güvenirlik çalışması, aynı kişiler tarafından Hacettepe Üniversitesi, Eğitim Fakültesi'nde yapılan çalışma ile sağlanmıştır (Aşkar ve Akkoyunlu, 1993).

Araştırmacının çalışmasında bu envanteri kullanmasının nedeni; Türkçe'ye uyarlanması, geçerlik ve güvenirlik çalışmasının yapılması ve 
araştırmacının da dahil olduğu (Erkan Yazıcı\&Yazıcı, 2011) bir çok çalışmada uygulanmış olmasıdır.

Envanter, 4'er seçenekli 12 maddeden oluşmaktadır. Öğrencilerden kendi için en uygun olana 4, en az uygun olana 1 verecek şekilde her bir maddeyi kendi içinde değerlendirmeleri istenmiştir.Değerlendirme için her seçeneğe verilen değer (SK, SY, AY, YG) ayrı bir şekilde toplanır ve 12 ile 48 puan arasında birsonuç elde edilir. Daha sonra, SK-SY "soyut kavramsallaştırma- somut yaşantı" ve AY-YG"aktif yaşantı- yansıtıcı gözlem" formülleri kullanılarak -36 ile +36 arasında değişen puanlarelde edilir. SK-SY'de elde edilen pozitif puan öğrenmenin soyut, negatif bir puan ise öğrenmenin somut olduğunu göstermektedir. Aynı şekilde AY-YG'de elde edilen pozitif puanlar öğrenmenin aktif, negatif puanlar ise yansıtıcı olduğunu göstermektedir. Şekil 2'de gösterilen diyagramda iki puanın kesiştiği nokta bulunarak bireye en uygun olan öğrenme stili belirlenmektedir (Kolb, 1999).

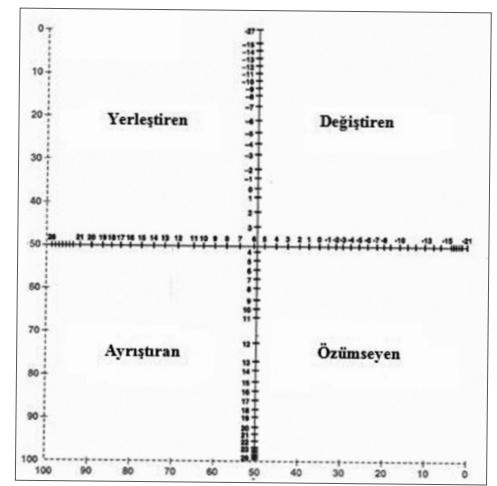

Şekil 2: Kolb'un Öğrenme Stili Envanterinin değerlendirilmesi (Kolb, 1999)

Kolb öğrenme stili envanteri kullanılarak özellikle eğitim bilimleri alanında bir çok çalışma yapılmıştır. Bu araştırma için önemli olan bazı çalışmalar ve elde edilen sonuçlar aşağıda kısaca açıklanmıştır:

Erkan Yazıcı ve Yazıcı (2011), Mimarlık öğrencilerinin Mekanik ve Mukavemet derslerindeki başarılarını öğrenme stilleri ile karşılaştırmıştır. 53 öğrencinin katıldığı çalışmada öğrencilere Kolb öğrenme stili anketi uygulanmıştır. Karşılaştırma neticesinde en başarılı olan öğrencilerin ayrıştıran öğrenme stiline sahip olduğu, en başarısız olan öğrencilerin ise 
değiştiren öğrenme stiline sahip olduğu tespit edilmiştir. Araştırma sonucu, adı geçen stillerin literatürdeki özelliklerine uygun sonuç vermektedir.

Demirbaş ve Demirkan (2003), tasarım öğrencilerinin öğrenme stillerinin, tasarımın farklı aşamalarındaki başarıları üzerindeki etkilerini deneysel birçalışma ile tespit etmeye çalışmışlardır. Deneysel çalışma Bilkent Üniversitesi iç̧ Mimarlık ve ÇevreTasarımı bölümündeki öğrencilerle yapılmıştır. İlk olarak, öğrencilerin öğrenme stilleri, "Kolb Öğrenme Stilleri Envanteri"ne göre belirlenmiştir. Daha sonra 4 aşamalı deneysel bir çalışma yapılmıştır. Bu çalışmadan elde edilen sonuçlarda, öğrenmede tercih edilen yaklaşımın tasarımın farklı aşamalarındaki başarısı üzerinde etkili olduğu ifade edilmiştir. Öğrenme stilleri göz önüne alındığında"özümseyen"lerin tasarım süreci boyunca en çok ilerlemeyi kaydeden grup olduğu, "yerleştiren"lerin ise ilk aşamada daha yüksek başarı göstermelerine rağmen daha ileri aşamalarda performanslarının azaldığı belirtilmiş̧tir.

Hearron (1991) tarafından, East Texas State üniversitesinde Anatomi ve Fizyoloji derslerini alan öğrencilerin öğrenme stillerinin, mantıksal düşünme düzeylerinin, giriş bilgilerinin ve değişik demografik özelliklerinin, akademik başarıları üzerine etkisini belirlemek için bir araştırma yapılmıştır. Araştırma verileri, Tobin ve Capie'nin Mantıksal Düşünme Testi, A \& P İçerik Bilgisi Testi ve Kolb'un Öğrenme Stili Envanterinden elde edilen puanlar ve öğrencilerin akademik başarıları ile oluşturulmuştur. Araştırma sonucunda, söz konusu dersleri alan öğrencilerin akademik başarıları ile yaş, mantıksal düşünme, giriş bilgisi ve öğrenme stillerinden soyut kavramsallaştırma arasında istatistiksel olarak anlamlı bir ilişki bulunmuştur.

Ismail (1982) tarafından Northern Illinois Üniversitesi'ne devam eden öğrencilerin başarı güdüleri ve öğrenme stilleri arasındaki ilişkiyi tespit etmek amacıyla bir araştırma yapılmıştı. Araştırmada veri toplama aracı olarak Mehrabian and Bank's Başarma Eğilimi Ölçeği ve Kolb'un Öğrenme Stili Envanteri kullanılmıştır. Çalışma sonunda farkı akademik alandaki öğrencilerin başarı güdüleri ve öğrenme stilleri arasında anlamlı bir ilişki tespit edilmiştir. 
Bu bilgiler ışığında, Mimarlık Bölümü öğrencilerinin gördüğünü kağıda aktarma aşamasında elde edilen farklııkların öğrenme stilleriyle ilişkili olabileceği düşünülmüştür.

\section{Atölye Çalışması}

Çalışma, 2013-2014 güz yarıyılı, İstanbul Kültür Üniversitesi, Mimarlık Bölümünde yer alan Mimari Perspektif dersine katılan 11 öğrenci ile yapılmıştır. Öğrencilere ilk olarak 12 sorudan oluşan Kolb Öğrenme Stili Envanteri yaptırılmıştır. Daha sonra Kuzguncuk'da bulunan iki sokağın kesişmesinden oluşan köşeden çekilmiş bir fotoğraf (Fotoğraf 1) panoya yansıtılmıştır. Fotoğraf sokakta duran yaklaşık 165 $\mathrm{cm}$. boyutlarında bir kişi tarafından çekilmiştir. Yani ufuk çizgisi yaklaşık olarak yerden $155 \mathrm{~cm}$ yukarıdadır. Öğrencilerden 30 dakika süre içerisinde, daha önce öğrendikleri iki kaçış noktalı perspektif çizme kurallarından yararlanarak, verilen fotoğrafı kağıda aktarmaları istenmiştir. Yapılan çalışma sonuçları belirli kriterlere göre değerlendirilerek, öğrencilerin öğrenme stilleri ile karşılaştırılmıştır.

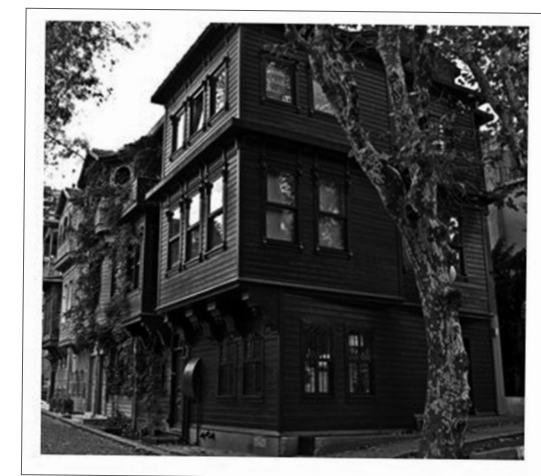

Fotoğraf 1:Kuzguncuk'da bir sokak (Erkan Yazıcı, 2013)

\section{Analiz ve Değerlendirme}

Kolb Öğrenme Stili Envanterinin değerlendirmesine göre; 3 öğrenci yerleştiren, 3 öğrenci değiştiren, 2 öğrenci ayrıştıran ve 3 öğrenci özümseyen öğrenme stiline sahiptir. Kolb öğrenme stili envanterinde aynı soru farklı şekillerde bir kaç kez sorulmuş, bu şekilde uygulayan kişinin daha dikkatli yanıt vermesi ve hata oranının minimuma düşmesi sağlanmaya çalışılmıştır. Öğrencilerin yapmış olduğu çizimler verilen 
fotoğraftaki detaylara göre analiz edilmiş ve öğrenme stillerine göre gruplandırılarak aşağıdaki tablolar elde edilmiştir (Tablo 1, 2, 3 ve 4).

Analiz yapılırken belirlenen kriterler, araştırmacının derste anlattığı, perspektif çizerken uyulması gereken maddelerin düzenlenmesiyle oluşturulmuştur.

Doğru bakış açısı:

Yerden yaklaşık $150 \mathrm{~cm}$ yukarıdan geçen ufuk çizgisi, ön planda bulunan konutun köşesinden bakılan bakış noktası ve iki sokağa doğru devam eden kaçış noktalarına göre çizildiğinde elde edilir.

Doğru oran:

Verilen fotoğraftaki en-boy ve dolu-boş oranları dikkate alınarak elde edilir.

Ağaç gövdesi:

Fotoğrafın ön planında bulunan büyük ağaç gövdesinin farkedilmesi sorgulanmaktadır.

Yeşil doku:

Ağaç ve konut yüzeyinde bulunan yeşil dokunun farkedilmesi sorgulanmaktadır.

Kaldırım:

Sokak boyunca devam eden kaldırımın farkedilmesi sorgulanmaktadır.

Yüzey dokusu (ilk yapı):

Fotoğrafta ön planda yer alan yapının yüzey dokusunun farkedilmesi sorgulanmaktadır.

Payanda (ilk yapı):

Fotoğrafta ön planda yer alan yapının payandalarının farkedilmesi sorgulanmaktadır.

Diğer yapıların varlığı:

Ön planda bulunan konutun sol tarafına doğru bitişik bir şekilde devam eden üç konutun varlığı sorgulanmaktadır. 
Yapılan çalışmalar öğrencilerin gösterdikleri performansın derecesine göre zayıf, ortalama ve iyi performans terimleri kullanılarak değerlendirilmiştir.

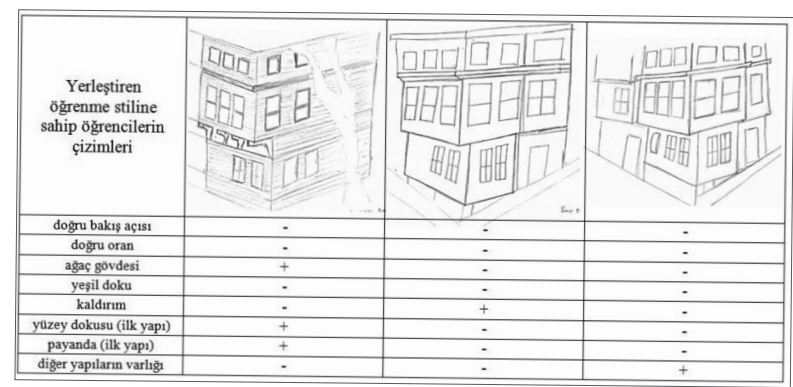

Tablo 1: Yerleştiren öğrenme stiline sahip öğrencilerin çizimlerinin analizi

Tablo 1'de gösterilen analize göre; yerleştiren öğrenme stiline sahip öğrencilerin hiçbiri doğru bakış açısında ve doğru oranda çizmemiştir. Diğer kriterler sorgulandığında da oldukça zayıf performans sergilendiği görülmüştür.

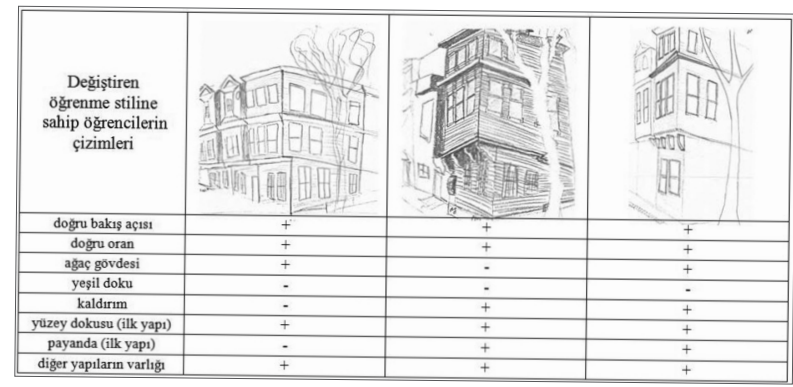

Tablo 2: Değiştiren öğrenme stiline sahip öğrencilerin çizimlerinin analizi

Tablo 2'de gösterilen analize göre; değiştiren öğrenme stiline sahip öğrencilerin tamamı doğru bakış açısında ve doğru oranda çizmiştir. Diğer kriterler sorgulandığında ortalama performans sergilendiği görülmüştür. 


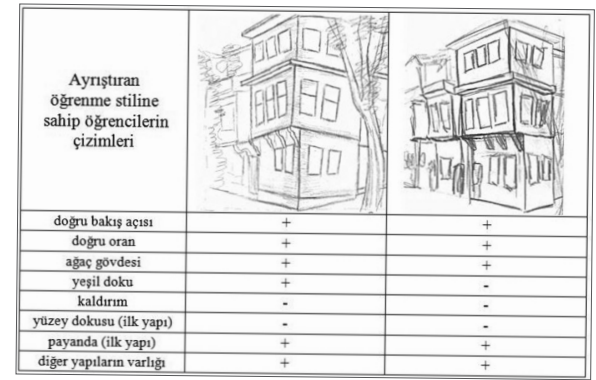

Tablo 3: Ayrıştıran öğrenme stiline sahip öğrencilerin çizimlerinin analizi

Tablo 3'de gösterilen analize göre; ayrıştıran öğrenme stiline sahip öğrencilerin tamamı doğru bakış açısında ve doğru oranda çizmiştir. Diğer kriterler sorgulandığında ortalama performans sergilendiği görülmüştür.

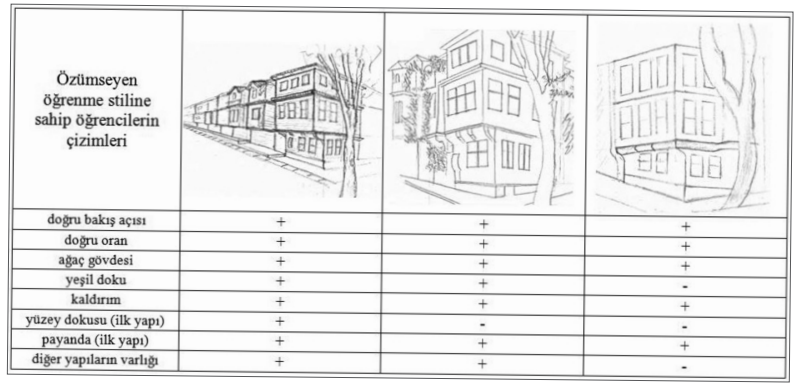

Tablo 4: Özümseyen öğrenme stiline sahip öğrencilerin çizimlerinin analizi

Tablo 4'de gösterilen analize göre; özümseyen öğrenme stiline sahip öğrencilerin tamamı doğru bakış açısında ve doğru oranda çizmiştir. Diğer kriterler sorgulandığında da oldukça iyi performans sergilendiği görülmüştür.

\section{Sonuç}

Perspektif çizimlerde ufuk çizgisi ve kaçış noktalarının yerinin belirlenmesi çok önemlidir. Ufuk çizgisinin ve kaçış noktalarının yanlış belirlendiği durumlarda farklı bakış açısında perspektifler elde edilmektedir. Yapılan çalışmada yerleştiren öğrenme stiline sahip öğrencilerin tamamı yanlış bakış açısında ve yanlış oranda çizerken, diğer 
stillere sahip öğrencilerin tamamı doğru bakış açısında ve doğru oranda çizmiştir.

Ağaç gövdesi, yeşil doku ve kaldırımınfarkedilip çizilmesi konusunda özümseyen öğrenme stiline sahip öğrenciler en iyi performansı gösterirken, yerleştiren öğrenme stiline sahip öğrenciler en zayıf performansı göstermişlerdir.

Ilk yapının yüzey dokusunu değiştiren öğrenme stiline sahip öğrencilerin tamamı çizerken, ayrıştıran öğrenme stiline sahip öğrencilerin hiç biri çizmemiştir.

Illk yapıda bulunan payandayı özümseyen ve ayrıştıran öğrenme stiline sahip öğrencilerin tamamı çizimlerinde gösterirken, yerleştiren öğrenme stiline sahip öğrencilerden sadece biri göstermiştir.

İlk yapının sol tarafında bulunan üç yapıyı değiştiren ve ayrıştıran öğrenme stiline sahip öğrencilerin tamamı gösterirken, yerleştiren öğrenme stiline sahip öğrencilerden sadece biri göstermiştir.

Tüm kriterlere genel olarak bakıldığında, yerleştiren öğrenme stiline sahip öğrenciler en zayıf performansı gösterirken, özümseyen öğrenme stiline sahip öğrenciler en iyi performansı göstermişlerdir. Özümseyen öğrenme stiline sahip öğrencilere yönelik elde edilen sonuçlar Demirbaş ve Demirkan'ın yaptığı çalışmanın sonuçlarıyla örtüşmektedir.

Yapılan literatür araştırmasında, özümseyen öğrenme stiline sahip bireylerin görsel sunumları içeren derslerde daha başarılı olduğu tespit edilmiştir. Dersin anlatılma yönteminde kullanılan görsel malzemeler ve yapılan uygulamalar neticesinde, özümseyen öğrenme stiline sahip öğrencilerin bu çalışmada daha başarılı olması bu tespiti destekler niteliktedir.

Öğrenme stillerinin belirlenmesi ile kişi kendi zayıf yönlerinin ya da potansiyellerinin farkına varabilir ve bu eksiklerini gidermek için ya da potansiyellerini açığa çıkarmak için çaba gösterebilir. Öğrenme stillerinin belirlenmesi dersin yürütücüsü için de yarar sağlayabilir. Bu şekilde dersin yürütücüsü öğrencilerin potansiyellerinin farkına varabilir, öğrencileri gruplara ayırabilir ve dersi öğrencilerin en iyi verim alabileceği şekilde düzenleyebilir. 
Öğrencinin bir derste başarılı olabilmesi sadece kendi öğrenme stili ile ilgili değildir. Aynı zamanda dersin yürütücüsünün sahip olduğu öğrenme stili de dersin başarısında etkili olabilir. Dersin yürütüsü ile öğrencinin aynı öğrenme stiline sahip olmasının ders başarısı üzerindeki etkisi de araştırılması gereken konulardan biridir. 


\section{Kaynakça}

Aşkar, Petek, Buket Akkoyunlu, "Kolb Öğrenme Stili Envanteri", Eğitim ve Bilim Dergisi, 87, 1993: 37-47.

Cesur, M., Onur, "Üniversite Hazırlık Sınıfı Öğrencilerinin Yabancı Dil ÖrenmeStratejileri, Öğrenme Stili Tercihi ve Yabancı Dil Akademik Başarısı Arasındaki Açıklayıcı ve Yordayıcı İlişkiler Örüntüsü",Yayınlanmamış doktora tezi, İstanbul:Yıldız Teknik Üniversitesi, Sosyal Bilimler Enstitüsü, 2008.

Demirbas, O., Osman, Halime Demirkan, "Focus on Architectural Design Process Through Learning Styles", Design Studies, 24(5), 2003: 437-456.

Ekici, Gülay, Öğrenme Stiline Dayalı Öğretim ve Biyoloji Dersi Öğretimine Yönelik Ders Planı Örnekleri, (1. Baskı) Ankara: Gazi Kitabevi, 2003.

Erkan Yazıcı, Yasemin, "Bilişsel Farklılıkların ve Mekansal Deneyimlerin İlk Yıl Mimarlık Öğrencilerinin Tasarım Süreçlerine Etkilerinin Araştırılması", Yayınlanmamış doktora tezi, Yıldız Teknik Üniversitesi, Fen Bilimleri Enstitüsü, Mimarlık Anabilim Dalı, Doktora Tezi, 2010.

Erkan Yazıcı, Yasemin, Gökhan Yazıcı, "The Effect of Learning Styles on the Performance of Architecture Students in Structural Design Courses", 2nd International Conference on New Trends in Education and Their Implications 2011, 27-29 Nisan, Antalya, 2011: 1677-1681.

Guild, Pat Burke, Stephen Garger,Marching to Different Drummers, ASCD, 2nd, Alexandria, USA, 1998.

Hearron, Mary, Carol, The Predictive Effect of Logical Thinking, Prior Knowledge, and Learning Style Characteristics On Academic Achievement in an Anatomy and Physiology Course,USA: East Texas State University, 1991. 
Ismail, Yusuf, "A Study of the Relationships Between Achievement Motivation and Learning Styles of a Group of Malaysian Students Attending Northern Illinois University",USA: Northern Illinois University, Yayınlanmamış Doktora Tezi, 1982.

Kolb, Alice, Y., Kolb, David, A, Learning Styles and Learning Spaces: Enhancing Experiential Learning in Higher Education, Academy of Management Learning \& Education, 4(2), 2005: 193-212.

Kolb, David, A., The Kolb Learning Style Inventory. New Jersey: Hay Resources Direct, 1999.

Kolb, David, A., Experiental Learning: Experience as the Source of Learning and Development, New Jersey: Prentice-Hall, 1984.

Öztuna, Seda, "Bilişsel Biçem ile Öğrenme Biçemi Arasındaki ilişki", Ekev Akademi Dergisi, yıl: 17 sayı: 56, 2013: 430.

Erkan Yazıcı, Yasemin, Fotoğraf 1: Kuzguncuk'da bir sokak, 2013. 